\title{
Historical Development of the CAMECA EPMA
}

\author{
Anne-Sophie Robbes ${ }^{1}$, Carl Henderson ${ }^{1}$, Mona Pierrette Moret ${ }^{1}$, David J Larson ${ }^{2}$ and Keith Baxter ${ }^{3}$ \\ 1. CAMECA, 29 quai des Grésillons 92622 Gennevilliers Cedex, France. \\ 2. CAMECA Instruments Inc., 5500 Nobel Drive, Madison, WI, USA \\ 3. AMETEK do Brazil - CAMECA BU, Rod. Eng ${ }^{\circ}$ Ermênio de Oliveira Penteado - Km 57, 13337-300 \\ Indaiatuba, Brazil
}

Sixty years since Castaing's thesis [1] establishing the technique, and more than fifty years since CAMECA's introduction of the first commercial instrument, Electron Probe Microanalysis (EPMA) still provides essential analytical capabilities at the leading edges of microanalytical application space. CAMECA's EPMA product line started with the MS85, and has been followed by the MS46, Camebax, SX50, SX100 and fifth-generation SXFive instruments (Figure 1). Furthermore, in recent years, the technique has not only maintained its relevance, but has expanded into new areas where detection limits and spatial resolution have been brought to new extremes. No longer exclusively a research laboratory technique, EPMA instruments may now be found running as fully-automated tools in the manufacturing environment.

Over the past few decades, the limits of the technique have been pushed systematically in various directions. Applications such as thin films and particles require hardware capabilities different from those used in high voltage, high current trace element applications. The problem for equipment manufacturers has been to devise hardware capable of supporting a wide diversity of applications without excessive specialization. In recent years, advanced applications for EPMA have moved toward high current, low voltage applications for trace element quantification at high spatial resolution. Concurrently, CAMECA has introduced a low-voltage EPMA to the semiconductor industry for implants, dopants and thin films, which has required a specialized understanding of low voltage X-ray phenomena. The development of the Schottky emitter and its implementation as electron source in the field of electron microprobe has significantly improved the characterization of materials in earth sciences, metallurgy and the ceramic industry (Figure 2). In this example, the improvement of the imaging resolution as a function of impact energy is illustrated in the $\mathrm{Al} \mathrm{K \alpha} \mathrm{X}$-ray maps of a brass specimen at progressively lower electron beam energies.

The strength of an Electron Probe Microanalysis lies in its ability to measure accurately and quantify elements with concentrations from major to trace levels of a few 10's ppm. The Field Emission Source allows analysis of both major and trace elements at high beam currents, thanks to the high brightness of the source and the excellent stability of the beam current, with the added advantage of increased spatial resolution at low beam voltages [2].

[1] R. Castaing, Application of electron probes to local chemical and crystallographic analysis. PhD Thesis, University of Paris, 1951. English translation by Duwez P and Wittry DB, California Institute of technology, 1955.

[2] C. Hombourger and M. Outrequin, Micros Today 21 (2013), p. 10. 

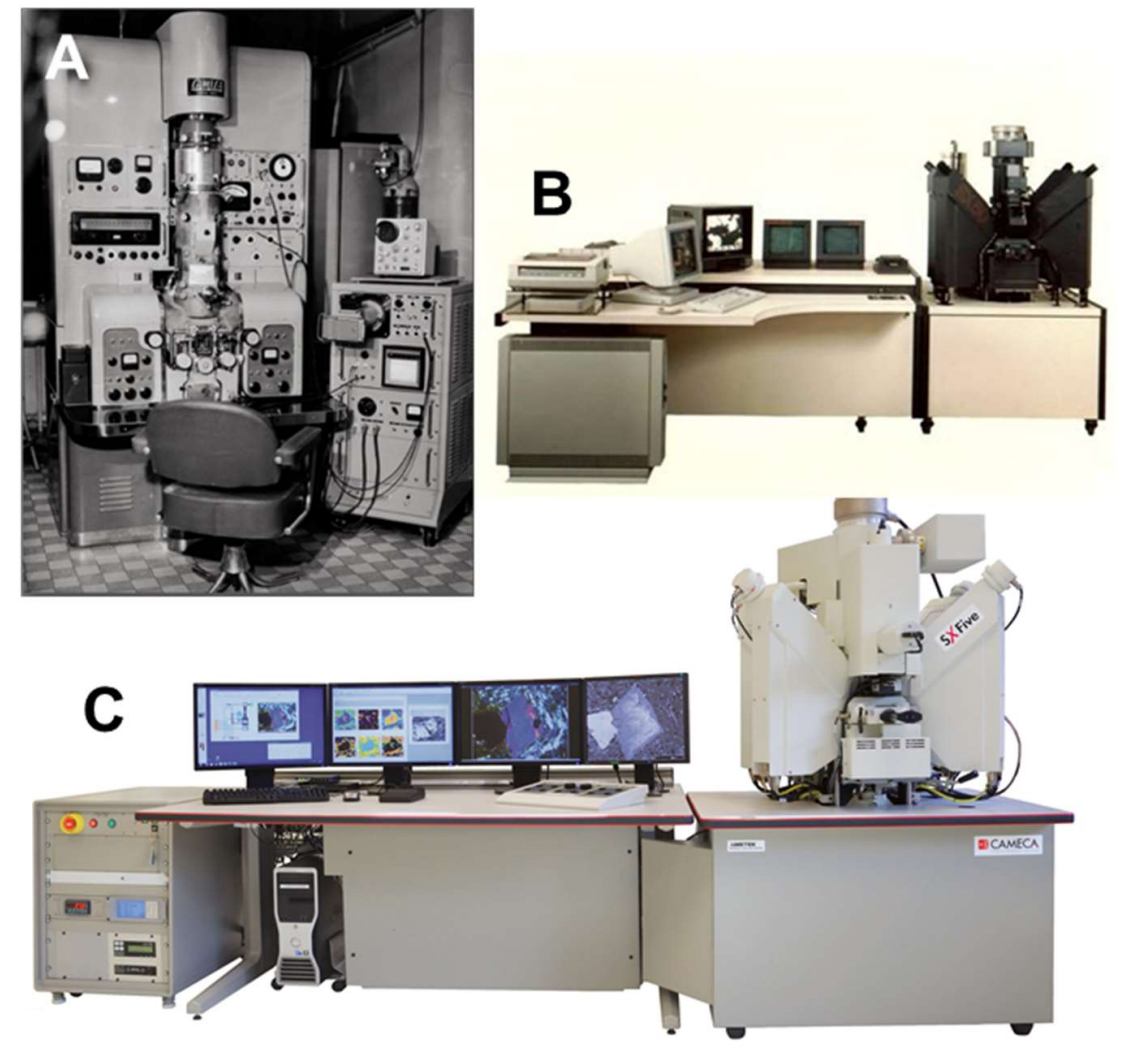

Figure 1. (a) The MS85 - The first model of commercial EPMA. (b) The SX-50 1986. (c) The SXFive CAMECA's latest EPMA generation.

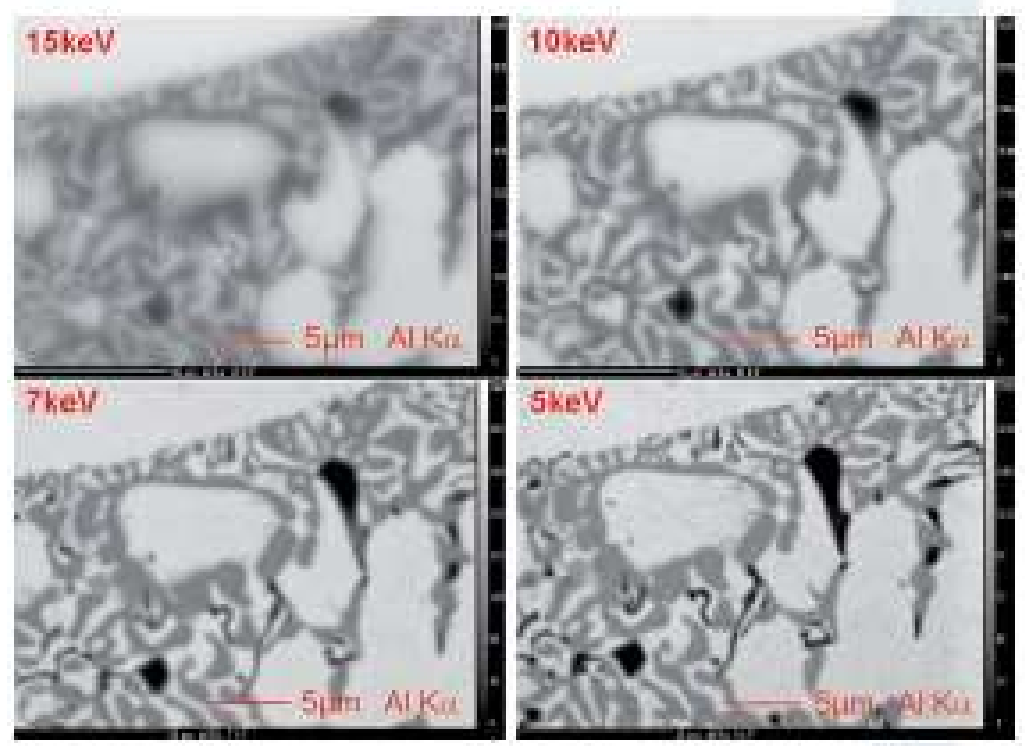

Figure 2. The improvement of the analytical resolution as a function of impact energy is illustrated in the $\mathrm{Al} \mathrm{K} \alpha \mathrm{X}$-ray maps of a brass specimen at progressively lower electron beam energies: 15 to $5 \mathrm{keV}$. The highest analytical resolution is achieved at $5 \mathrm{keV}$ and a beam diameter of $80 \mathrm{~nm}$. 